\title{
Development of a genetically-encoded biosensor for detection of polyketide synthase extender units in Escherichia coli
}

\author{
Edward Kalkreuter ${ }^{1,2,3}$, Aaron M. Keeler ${ }^{1, \dagger}$, Alexandra A. Malico ${ }^{1, \dagger}$, Kyle S. Bingham ${ }^{1,4}$, \\ Anuran K. Gayen ${ }^{1}$, Gavin J. Williams ${ }^{1,2,{ }^{*}}$ \\ ${ }^{1}$ Department of Chemistry, NC State University, Raleigh, North Carolina 27695, United States \\ ${ }^{2}$ Comparative Medicine Institute, NC State University, Raleigh, North Carolina 27695, United \\ States \\ ${ }^{3}$ Present address: Department of Chemistry, The Scripps Research Institute, Jupiter, Florida \\ 33458, United States \\ ${ }^{4}$ Present address: UNC Chapel Hill School of Medicine, Chapel Hill, North Carolina 27516, United \\ States
}

\begin{abstract}
The scaffolds of polyketides are constructed via assembly of extender units based on malonyl-CoA and its derivatives that are substituted at the $\mathrm{C} 2$-position with diverse chemical functionality. Subsequently, a transcription factor-based biosensor for malonyl-CoA has proven to be a powerful tool for detecting malonyl-CoA, facilitating the dynamic regulation of malonyl-CoA biosynthesis, and guiding high-throughput engineering of malonyl-CoA dependent processes. Yet, a biosensor for the detection of malonyl-CoA derivatives has yet to be reported, severely restricting the application of high-throughput synthetic biology approaches to engineering extender unit biosynthesis and limiting the ability to dynamically regulate the biosynthesis of polyketide products that are dependent on such a-carboxyacyl-CoAs. Herein, the FapR biosensor was reengineered and optimized for a range of $\mathrm{mCoA}$ concentrations across a panel of $E$. coli strains. The effector specificity of FapR was probed by cell-free transcription-translation, revealing that a variety of non-native and non-natural acyl-thioesters are FapR effectors. This FapR promiscuity proved sufficient for the detection of the polyketide extender unit methylmalonyl-CoA in E. coli, providing the first reported genetically encoded biosensor for this important metabolite. As such, the previously unknown broad effector promiscuity of FapR provides a platform to develop new tools and approaches that can be leveraged to overcome limitations of pathways that construct diverse a-carboxyacyl-CoAs and those that are dependent on them, including biofuels, antibiotics, anticancer drugs, and other value-added products.
\end{abstract}

\section{Graphical Abstract}

*Corresponding author, gjwillia@ncsu.edu.

$\dagger$ These authors contributed equally.

SUPPORTING INFORMATION

Includes supplementary tables, supplemental figures, and detailed methods that describe the synthesis of mmSNAC, dose-response of the cell-free TX-TL assay and electrophoretic mobility shift assay. 


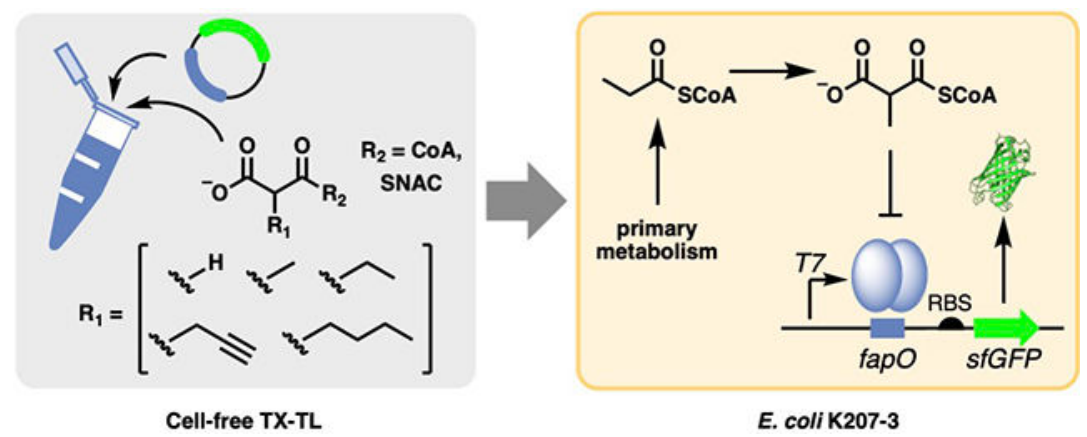

\section{Keywords}

malonyl-CoA; polyketide; biosensor; transcription factor; synthetic biology

\section{INTRODUCTION}

Engineered bacterial transcriptional regulators have contributed immensely to chemical and synthetic biology by providing highly modular and tunable devices for sensing small molecules. ${ }^{1-3}$ By coupling them to fluorescent or chromogenic readouts, transcription factor-based biosensors have been applied as tools that detect key metabolites, regulate biosynthetic circuits, guide metabolic engineering, and enable directed evolution of enzymes and pathways. ${ }^{4-7}$ Yet, biosensors for the detection of natural products and their biosynthetic precursors are not yet widely available, limiting the ability of high-throughput strategies to be applied to many important classes of molecules. For instance, malonyl-CoA ( $\mathrm{mCoA}$, Figure 1) plays an integral role in cellular primary and secondary metabolism as a building block for fatty acids, phenylpropanoids, polyketides, and hybrid natural products. ${ }^{8}$ Because of this, mCoA biosynthesis has been a longstanding target of metabolic engineering efforts. 9-13 Accordingly, genetically-encoded biosensors for the detection of mCoA have been constructed using FapR, a transcriptional regulator found in nearly all Gram-positive bacteria and acts as a global regulator for fatty acid biosynthesis. ${ }^{14}$ FapR has been characterized as the only member of its regulator family owing to its unique, highly-dynamic structure. ${ }^{15,16}$ Crystal structures of FapR indicate a dimer, whereby each monomer is comprised of a C-terminal ligand-binding domain and an $\mathrm{N}$-terminal domain that binds to its cognate DNA operator, fapO. Dependent on the promoter, FapR has been shown to act as either an activator or a repressor in the presence of its native ligand, mCoA. ${ }^{17}$

Given its utility as a transcriptional regulator, FapR has been developed and utilized as a mCoA biosensor in several hosts including E. coli, ${ }^{17-19}$ yeast, ${ }^{20,21}$ and mammalian cells. ${ }^{22}$ The first reported FapR biosensor in E. coli utilized the fapR gene from Bacillus subtilis cloned under $\mathrm{T} 7$ and LacI control alongside an eGFP reporter gene regulated by T7, LacI, and FapR (Figure 2A). ${ }^{18}$ This FapR biosensor, while not initially optimized for a high signal-to-noise ratio, crucially established that a FapR biosensor could be used to quantify $\mathrm{mCoA}$ over a linear range suitable for most in vivo applications. The next iterations of the FapR biosensor in E. coli utilized a T7 promoter (FapR as a repressor) and a pGAP promoter (FapR as an activator) to balance fatty acid biosynthesis against mCoA biosynthesis. ${ }^{17}$ These 
biosensors were subsequently built with varying numbers of fapO sites placed downstream of the reporter gene promoter, with the most sensitive of these unsurprisingly containing only a single operator sequence. FapR and LacI were also leveraged to create a fatty acid production negative feedback loop to alleviate the toxicity from acetyl-CoA carboxylase (acc) overexpression, leading to a one-third improvement in fatty acid titer in E. coli. ${ }^{19}$

Notably, none of the previously reported FapR-based mCoA biosensors were utilized for detection of ligands beyond mCoA. Subsequently, they have been leveraged only for control of fatty acid products. Indeed, compounds related to mCoA such as acetyl-CoA, propionylCoA, succinyl-CoA, and butyryl-CoA have been reported to be non-effectors of FapR. ${ }^{15}$ Furthermore, despite the important role of $\mathrm{mCoA}$ derivatives substituted at the $\mathrm{C} 2$ position as extender unit building blocks for many biologically-relevant polyketides (Figure 1), 12, 23-25 genetically-encoded biosensors for $\mathrm{C} 2$-derivatives of $\mathrm{mCoA}$ have yet to be reported. Biosensors for such a-carboxyacyl-CoAs could be leveraged to optimize natural or artificial pathways that synthesize them in heterologous hosts. ${ }^{26}$ Such sensors could also be used to dynamically regulate metabolic pathways that supply or consume natural or non-natural $\mathrm{mCoA}$ derivatives and lead to improvements in product titers of polyketide-derived metabolites that are dependent on natural or non-natural extender units.

Herein, we describe a FapR biosensor that requires no exogenous effectors (e.g., IPTG) and is optimized for a range of $\mathrm{mCoA}$ concentrations across a panel of E. coli strains. We also describe the development of a powerful cell-free transcription-translation assay to probe the effector specificity of FapR towards a variety of non-native and non-natural acyl-thioesters. This enabled, for the first time, the discovery that the redesigned and optimized FapR-based biosensor detects several $\mathrm{mCoA}$ derivatives modified at the $\mathrm{C} 2$-position, providing a platform for the evaluation and evolution of the pathways necessary for their biosynthesis. Finally, we demonstrated the ability of the biosensor to detect the non-native polyketide extender unit mmCoA produced in E. coli. In addition to detection and monitoring acylCoAs for chemical biology applications, biosensors with broad effector specificities also offer new opportunities to overcome limitations of pathways that construct diverse acarboxyacyl-CoAs and those pathways that depend on them.

\section{RESULTS AND DISCUSSION}

\section{Refactoring the FapR Operon for an Efficient Prototype Malonyl-CoA Biosensor}

Previously published E. coli malonyl-CoA biosensors were based on FapR as a repressor (with the addition of a second effector molecule, e.g. IPTG) or FapR as an activator. ${ }^{17-19}$ Thus, these biosensors have been limited in their ability to be coupled with other protein expression systems and unnecessarily increase the metabolic burden on the host strain. To address this constraint, a biosensor construct was desired that required no external inputs to function and that was robust enough to use as a template for directed evolution of FapR or other proteins of interest. Towards this end, a new plasmid, pSENSE2FF, was designed based on our previously described macrolide biosensor. ${ }^{4}$ Two constitutive lac promoters, Pro $_{\text {sfGFP }}$ and ProfapR (pLacIQ), ${ }^{4}, 27$ control the transcription of a fluorescent reporter gene (super-folder GFP, $s f G F P$ ) and a codon-optimized version of the fapR gene from B. subtilis,

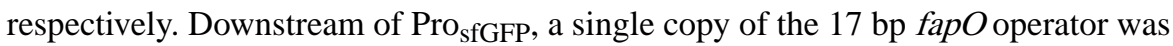


introduced to afford FapR control of reporter transcription (Figure 2B and Supplementary Table S1). Superfolder GFP (sfGFP) was selected due to its higher brightness, rapid folding, and low photobleaching compared with other GFP variants. ${ }^{28}$

\section{In Vivo Optimization of the Prototype Malonyl-CoA Biosensor}

Following the construction of the prototype refactored biosensor system, an in vivo assay utilizing cerulenin was developed to determine its fold activation. Because mCoA is not cellpermeable, it is not possible to directly manipulate its intracellular concentration. Cerulenin acts as an equimolar inhibitor of the $\beta$-keto-acyl-ACP synthase and causes a build-up of intracellular mCoA due to its inability to be processed to fatty acids. ${ }^{29}$ The linear response of [mCoA] to [cerulenin] has been previously established for the concentrations used here. ${ }^{18}$ The fold activation of the prototype biosensor strain (RBS 1A1) in response to mCoA was determined by measuring sfGFP fluorescence in the presence and absence of cerulenin supplemented to the culture media, revealing a modest activation ratio ( $\sim 5$-fold, Figure 3$)$. Thus, the prototype biosensor required further optimization to enhance its sensitivity and fold-activation. It was hypothesized that lower concentrations of FapR would result in higher fluorescence output at a fixed concentration of mCoA.$^{30-32}$ Therefore, the RBS of fapR was targeted for mutagenesis by designing an 18-member RBS variant library with a maximum calculated transcription initiation rate (TIR) equal to that of the RBS of 1A1 (7,594 au). The fold-activation of $\sim 300$ members of the fapR RBS library was determined by again leveraging cerulenin to enhance the intracellular concentration of mCoA (Figure 3). As predicted, most RBS variants resulted in significantly higher activation than the prototype $1 \mathrm{~A} 1$ construct, with some reaching $>60$-fold activation under the assay conditions (Figure $3)$.

Several variants were selected from the FapR RBS library and their dose-response curves with cerulenin determined in E. coli DH5a (data not shown). One notable variant, 2H8, predicted to have the weakest calculated RBS (TIR $=171 \mathrm{au}$ ), provided a higher fluorescence output than $1 \mathrm{~A} 1$ across the entire range of cerulenin concentrations assayed. The variant $2 \mathrm{H} 8$ also displayed a robust activation ratio ( $\sim 34$, Table 1$)$ and provided a maximal fluorescent response of 58,000 RFU (relative fluorescence units) that was more than 3-fold higher than that of 1A1 (Figure 4 and Table 1). Notably, this advantage came with the side effect of a leaky OFF state of $\sim 1,400 \mathrm{RFU}, \sim 6$-fold higher than that of $1 \mathrm{~A} 1$, such that the $K_{1 / 2}$ of $2 \mathrm{H} 8$ with cerulenin was indistinguishable from that of $1 \mathrm{~A} 1$ in this strain (Table 1). Nevertheless, this RBS engineering approach quickly arrived at a variant biosensor with the desired improvement in detection ability across a range of cerulenin concentrations.

\section{FapR-Based Detection of Malonyl-CoA Across Various E. coli Strains}

The FapR-based biosensor inherently accounts for basal levels of ligand as mCoA is required for cell growth and is always present. However, the contribution of background $\mathrm{mCoA}$ to overall biosensor activity under other conditions cannot be easily subtracted because the levels of mCoA fluctuate significantly during growth of a culture. ${ }^{17}$ Moreover, the effect of the inhibitor cerulenin across various strains of $E$. coli might not be consistent. To determine whether the engineered FapR biosensor response is dependent on the host 
strain, the best performing variant $2 \mathrm{H} 8$ was also transformed into E. coli $10 \mathrm{G}$ and $E$. coli TOP10, and the cerulenin dose-response curves determined. Notably, there are differences in how the three $E$. coli strains respond to cerulenin and consequently, the dose-response curves for each strain are significantly different (Figure 4 and Table 1 ). For example, the maximum fluorescence output of the FapR biosensor in E. coli TOP10, 10G, and DH5a is reached at $\sim 30, \sim 50$, and $\sim 75 \mu \mathrm{M}$ cerulenin, respectively (Table 1). In addition, the fluorescence output of the FapR biosensor in E. coli TOP10 at high concentrations of cerulenin $(>50 \mu \mathrm{M})$ is significantly lower than that in E. coli DH5a or $10 \mathrm{G}$ (Figure 4). Thus, the FapR biosensor performs differently across various $E$. coli strains during growth of the culture but crucially always out-performs the prototype 1A1 in E. coli DH5a (Figure 4). The strain-specific dose-response curves might be a consequence of several factors, including unique FapR expression levels, unique sensitivity to cerulenin, or strain-dependent levels of mCoA in each strain. However, given that too much mCoA is toxic to the cell, ${ }^{33,34}$ a culture with higher endogenous levels of mCoA is expected to result in both improved sensitivity to cerulenin and a lower fluorescence at lower concentrations of cerulenin. Interestingly, the few genomic differences between these strains are likely insufficient to directly explain large differences in mCoA production levels (Supplementary Table S2). Regardless, the overall robust performance of the FapR 2H8 biosensor across several strains of E. coli indicates that the engineered prototype biosensor is a good starting point for development of a tool for detection of other malonyl-CoA derivatives.

\section{Probing the Effector Promiscuity of FapR by Cell-Free Transcription-Translation}

Aside from mCoA, the ability of other a-carboxyacylmalonyl-CoAs to activate FapR has not been previously reported. Analysis of the crystal structure of FapR reveals that the terminal carboxylate of $\mathrm{mCoA}$ is a major factor in effector-binding specificity, forming a salt-bridge with the side-chain of Arg106, and is facilitated by a nearby Phe99 side-chain and Glu73' backbone carbonyl (Figure 5A). In addition, the thioester of mCoA binds to the side-chain of Asn $115,{ }^{15}$ Notably, while the side-chain of Phe99 orients almost directly towards the a-carbon of mCoA (distance between Phe99- $\mathrm{C}_{4}$ and mCoA- $\mathrm{C}_{\alpha}$ is $\sim 3.2 \AA$ ), there is room for substituents in place of the a-hydrogens of mCoA (especially in place of the pro-R hydrogen). Moreover, the loops that form the majority of the ligand binding pocket are disordered in the ligand-free FapR structure which indicates this region is highly dynamic. ${ }^{15}$ The lack of residues to restrict potential mCoA $a$-substituents coupled with the conformational flexibility suggests that $\mathrm{mCoA}$ derivatives might be FapR effectors. Accordingly, a series of mCoA derivatives with various alkyl and alkynyl functionalities at the C2-position was designed to probe the effector promiscuity of FapR and included methylmalonyl-CoA ( $\mathrm{mmCoA})$, ethylmalonyl-CoA (emCoA), propargylmalonyl-CoA (pgmCoA), and butylmalonyl-CoA (bmCoA) (Figure 5B). Furthermore, the 3'-phosphonucleoside moiety of $\mathrm{mCoA}$ is solvent exposed (Figure 5A), suggesting that a large portion of $\mathrm{CoA}$ is not required for de-repression of FapR. Accordingly, the truncated analogue mmSNAC was synthesized to test this hypothesis (Figure 5B).

Assessing the effector promiscuity of FapR in vivo with the panel of mCoA analogues is challenging for several reasons. First, acyl-CoAs are not cell-permeable and cannot be introduced exogenously. Second, pathways for assembling most non-native mCoA 
derivatives in E. coli have yet to be developed, limiting the high-level in situ biosynthesis of the selected acyl-CoAs. To circumvent these issues, a cell-free transcription-translation (TXTL) approach was developed that could accurately control the concentration of $\mathrm{mCoA}$ within the assay. ${ }^{35,} 36$

To this end, the reporter module of the FapR 2H8 biosensor was cloned into pET28a, replacing the typical $\mathrm{lacO}$ site controlling the $\mathrm{T} 7$ promoter with a single fapO $O$ binding site upstream of the $s f G F P$ gene, producing pET28a-T7-fapO-sfGFP (Figure 5C). Each acarboxyacyl-CoA was generated enzymatically from the corresponding malonic acid and CoA using the wild-type malonyl-CoA synthetase MatB or the engineered MatB variant, T207G/M306I. ${ }^{37,} 38$ Next, the response of the cell-free TX-TL biosensor assay was evaluated by using various concentrations of MatB-generated native effector, $\mathrm{mCoA}$, along with a fixed amount of purified FapR and T7-fapO-sfGFP. The fluorescence output of the cell-free biosensor was approximately linear up to $150 \mu \mathrm{M}$ mCoA (Supplementary Figure S1) and is consistent with previously reported in vitro transcription activities and binding affinities of FapR and mCoA. ${ }^{39}$ In addition, the maximum fluorescence signal was $~ 15$-fold greater than that in the absence of mCoA. Furthermore, to account for potential inhibition of the cell-free biosensor by the MatB reaction mixture, the FapR system was also assayed using a commercial standard of mCoA. Notably, there was no significant difference in the fluorescence output of the cell-free FapR biosensor measured in the presence of the MatBgenerated or commercial mCoA (Supplementary Figure S1). Together, these data indicate that the cell-free TX-TL assay is suitable to probe the effector promiscuity of FapR with MatB-generated xmCoAs.

Next, the cell-free FapR biosensor was assayed with each a-carboxyacyl-CoA at a fixed concentration $(150 \mu \mathrm{M})$. Notably, the fluorescence response with mmCoA was statistically indistinguishable from that with the native ligand, $\mathrm{mCoA}$ (Figure 5D). Furthermore, the ethyl (emCoA), propargyl (pgmCoA), and butyl (bmCoA) derivatives of mCoA were all also identified as effectors, as judged by the cell-free fluorescence data. The ability of pgmCoA to de-repress FapR/T7-fapO-sfGFP was indistinguishable from that of $\mathrm{mCoA}$ and $\mathrm{mmCoA}$ under the assay conditions used. The saturated alkyl derivatives emCoA and bmCoA were the poorest effectors, based on the fluorescence data. This robust activity of pgmCoA may be due in part to the increased rigidity of the alkyne side-chain or additional interactions of the alkynyl $\pi$ electrons with the FapR ligand-binding site, perhaps with the $\pi$-rich side-chain of the nearby Phe99 (Figure 5A). Gratifyingly, as previously reported, ${ }^{15}$ de-repression was not observed in the presence of propionyl-CoA and was indistinguishable from the (-) thioester control. To provide further evidence that FapR is de-repressed by derivatives of mCoA, FapR was tested in vitro for DNA-binding and release by electrophoretic mobility shift assay (EMSA) in the presence of mCoA or mmCoA. Using purified wild-type FapR protein, EMSA was run with a $40 \mathrm{bp}$ DNA fragment containing the fapO binding site (Supplementary Figure S2). Incubation of the DNA fragment with a two-fold excess of FapR resulted in near-complete binding and a corresponding gel shift. Next, to determine the concentration of $\mathrm{mCoA}$ at which half of the DNA would be bound, various concentrations of mCoA were titrated against FapR, revealing that $200 \mu \mathrm{M}$ was required for this (data not shown). Incubation with the FapR-fapO complex with mmCoA achieved a similar level of 
de-repression as that observed with $\mathrm{mCoA}$ (Supplementary Figure S2). Together, the in vitro data confirm the ability of mmCoA to de-repress the FapR system.

In addition to the full-length a-carboxyacyl-CoAs, the truncated analogue mmSNAC was determined to be an effector, although it provided $\sim 50 \%$ the de-repression activity of the corresponding CoA thioester, based upon the fluorescence assay (Figure 5D). Thus, even though a large portion of CoA is solvent exposed, some of the amide portion of CoA is still required for optimal de-repression of FapR. Remarkably, and consistent with our structuredriven hypothesis, these data indicate that the promiscuity of FapR extends beyond the previously-established native effector $\mathrm{mCoA}$ and includes non-native and non-natural malonyl-thioesters.

\section{FapR-Based Detection of Methylmalonyl-CoA in vivo}

The discovery that FapR is de-repressed by several non-native malonyl-CoA derivatives in vitro prompted us to consider whether the effector promiscuity of FapR could be leveraged to detect non-native acyl-CoAs inside living cells. As an initial test for FapR detection of derivatives of $\mathrm{mCoA}$ in vivo, a previously established and engineered $E$. coli strain optimized for high-level production of methylmalonyl-CoA ( $\mathrm{mmCoA})$ was selected for analysis. ${ }^{23}$ E. coli K207-3 includes the propionyl-CoA carboxylase (PCC) genes $p c c B$ and accA1 from Steptomyces coelicolor under T7 polymerase/LacI control, allowing for production of $\mathrm{mmCoA}$ from propionate when induced with IPTG, while endogenous $\mathrm{mCoA}$ levels remain unchanged. ${ }^{40}$ Accordingly, the FapR biosensor $2 \mathrm{H} 8$ was introduced into the K207-3 strain, and the fluorescence output was determined in the presence or absence of IPTG/sodium propionate supplemented to the growth media. As expected, in the absence of IPTG, the fluorescence output was low $(\sim 2,000 \mathrm{RFU})$ and similar to the background fluorescence of $2 \mathrm{H} 8$ in E. coli TOP10, 10G, and DH5a in the absence of cerulenin (Figure 6). Upon induction of the PCC genes with IPTG, the fluorescence ouput increased significantly (>15,000 RFU), even in the absence of supplemental propionate (Figure 6). Furthermore, a small and statistically significant increase in fluorescence signal was observed when the culture media was supplemented with sodium propionate. This indicates that in the absence of enzymatic machinery to otherwise consume mmCoA, and as previously reported ${ }^{24}$ there is sufficient endogenous propionate and/or propionyl-CoA in K207-3 to drive mmCoA biosynthesis to levels detectable by the engineered FapR biosensor.

\section{DISCUSSION}

The FapR transcription factor has been used extensively to monitor its native effector, $\mathrm{mCoA}, 21,22$ and to regulate artificial genetic circuits that produce or consume mCoA. 17, 19, 20 Notably though, applications of FapR-based biosensors have been strictly limited due its assumed strict specificity for $\mathrm{mCoA}$, and genetically-encoded biosensors for derivatives of $\mathrm{mCoA}$ have yet be reported. To address this deficiency, we set out to first optimize the FapR biosensor by simplifying its circuit architecture and leveraging RBS mutagenesis to improve its ability to detect $\mathrm{mCoA}$ in E. coli. By testing the engineered biosensor across a series of $E$. coli strains, the impact of different cellular backgrounds was 
highlighted, revealing that some aspects of the FapR-based detection of mCoA are hostdependent. Next, we set out to probe the effector specificity of FapR beyond mCoA and prepared a panel of various a-carboxylmalonyl-thioesters via enzymatic or chemical synthesis. Crucially, a cell-free approach was developed to determine effector promiscuity with ligands that are otherwise cell impermeable. Moreover, the cell-free assay allowed the concentrations of each effector to be precisely controlled in the absence of other processes that might otherwise lead to fluctuations in their concentration over time. In this way, four additional CoA-thioesters were identified as effectors of FapR, including mmCoA, a metabolite native to $B$. subtilis. The biosensor was also shown to be de-repressed by an acarboxylmalonyl-SNAC, indicating that FapR could be harnessed to monitor intracellular levels of these chemically synthesized precursors that are frequently used as non-native and non-natural building blocks for polyketide biosynthesis. Remarkably, the native effector promiscuity of FapR was leveraged to detect $\mathrm{mmCoA}$ production in an engineered strain of E. coli, K207-3. It is notable that, even though the ability of $\mathrm{mCoA}$ and $\mathrm{mmCoA}$ to derepress FapR is indistinguishable (Figure 5D), the endogenous mCoA levels in K207-3 are not impacted by IPTG induction and/or propionate addition, so that the expected increase in mmCoA production upon induction is easily detected by the FapR biosensor in K207-3. This result demonstrates the ability of the FapR biosensor to detect fluctations in mmCoA in engineered microbial strains and paves the way to utilize this ability to guide improvements in $\mathrm{mmCoA}$ production and to develop strategies for dynamic metabolic control of $\mathrm{mmCoA}-$ dependent pathways. It is possible that further engineering of the FapR effector binding pocket would enable the detection of additional ligands or even specificity towards individual ligands, especially given the precedent of manipulating the effector specificity of other transcription factor based biosensors. ${ }^{4,41}$

Together, this work has indentified FapR as a tool for regulating metabolic pathways that produce or consume mmCoA. Moreover, the hitherto unknown ability of FapR to detect various a-carboxylmalonyl-CoAs now sets the stage for high-throughout engineering approaches such as directed evolution to be applied to enzymatic pathways responsible for the biosynthesis of natural or non-natural malonyl-CoA derivatives in diverse microbial hosts. ${ }^{26,42,43}$ In this way, we anticipate that FapR will prove an invaluable device to expand the scope and utility of a broad range of microbial based platforms for synthesis of products constructed from diverse polyketide extender units.

\section{MATERIALS AND METHODS}

\section{General}

Materials and reagents were purchased from Sigma Aldrich (St. Louis, MO) unless otherwise noted. Isopropyl $\beta$-D-thioglactoside (IPTG) was purchased from Calbiochem (Gibbstown, NJ). Primers were purchased from Integrated DNA Technologies (Coralville, IA). E. cloni 10G electrocompetent cells were purchased from Lucigen Corporation (Middleton, WI). Cerulenin was purchased from Cayman Chemical (Ann Arbor, MI), and stocks were dissolved in DMSO. Commercial malonyl-CoA and methylmalonyl-CoA were purchased from CoALA Biosciences (Austin, TX). All cultures were grown in LB media with $100 \mu \mathrm{g} / \mathrm{mL}$ ampicillin unless otherwise stated. Absorbance and fluorescence readings 
were taken in clear flat-bottom and black flat-bottom 96-well plates (Greiner Bio-One), respectively, in a BioTek Hybrid Synergy 4 plate reader, unless otherwise stated. All Sanger sequencing was performed by Genewiz, Inc. (South Plainfield, NJ).

\section{Construction of Plasmids}

The plasmid pSENSE2 was synthesized by Twist Bioscience (San Francisco, CA) in two fragments. The two pieces were assembled using standard restriction digestion and ligation procedures. The fapR_fapO fragment containing a codon-optimized fap $R$ gene and a fapO operator was synthesized by Genewiz, Inc. and cloned into pSENSE2 between the $K p n I$ and SpeI sites to give pSENSE2FF. FapR was amplified with a 5' $N c o$ I site and a 3' $X h o I$ site and cloned into pET28a to give fapR_pET28a (with a C-terminal His 6 tag). T7_fapO_sfGFP was constructed using GenScript GenBuilder (GenScript, Piscataway, NJ) according to the manufacturer's instructions with pET28a (amplified with T7forfapO.Gib1 and T7forfapO.Gib2, see entries 1-2, Supplementary Table S3) and fapO_sfGFP (amplified from pSENSE2FF with fapOforT7.Gib1 and fapOforT7.Gib2, see entries 3-4, Supplementary Table S3).

\section{RBS Library Construction and Screening}

The original fapR RBS 1A1 was calculated to have a transcription initiation rate (TIR) of 7,594 au using the Salis online RBS calculator. ${ }^{30-32}$ The calculator was used to design an 18-member RBS library with a maximum TIR of 7,594 au. Site-directed mutagenesis was also used to produce the RBS library (VRGAGGH) using the QuikChange II Site-Directed Mutagenesis protocol with the pSENSE2FF template and primers FapR_RBSLib2.SDM1 and FapR_RBSLib2.SDM2 (see entries 5-6, Supplementary Table S3). The reaction product was digested with $D p n I$ for $3 \mathrm{~h}$ at $37^{\circ} \mathrm{C}$ before electroporation into E. cloni® $10 \mathrm{G}$ electrocompetent cells (Lucigen). Transformed cells were plated on LB agar supplemented with $100 \mu \mathrm{g} / \mathrm{mL}$ ampicillin and incubated overnight at $37^{\circ} \mathrm{C}$. Individual colonies from the library were picked from LB agar plates and used to inoculate 93 wells of a 96-deepwell microplate with $500 \mu \mathrm{L}$ LB media supplemented with $100 \mu \mathrm{g} / \mathrm{mL}$ ampicillin. The remaining 3 wells were inoculated with colonies from pSENSE2FF RBS 1A1 that had been transformed into E. coli DH5a. Cultures were grown overnight at $37^{\circ} \mathrm{C}$ and $350 \mathrm{rpm}$, and $10 \mu \mathrm{L}$ from each well were used to inoculate $440 \mu \mathrm{L}$ LB media supplemented with 100 $\mu \mathrm{g} / \mathrm{mL}$ ampicillin. The new plates were grown for one hour at $37^{\circ} \mathrm{C}$ and $350 \mathrm{rpm}$. Plates were then treated with either $5 \mu \mathrm{M}, 12.5 \mu \mathrm{M}$, or $25 \mu \mathrm{M}$ cerulenin or the corresponding volume of DMSO. Plates were then grown an additional $15 \mathrm{~h}$. Plates were centrifuged at 3,500 rpm for $7 \mathrm{~min}$, and cell pellets were resuspended in $500 \mu \mathrm{L}$ PBS. $100 \mu \mathrm{L}$ from each well was used for analyzing optical density at $600 \mathrm{~nm}$ and sfGFP fluorescence (ex 485 $\mathrm{nm} / \mathrm{em} 509 \mathrm{~nm}$ ). Fluorescence values were divided by $\mathrm{OD}_{600}$ to yield growth-corrected relative fluorescence values. 279 individual colonies from the RBS library were screened at the different cerulenin concentrations.

\section{Expression and Purification of Mutant MatB}

The expression and purification of MatB T207G/M306I has been previously described ${ }^{37,38,44}$. Briefly, E. coli BL21(DE3) pLysS competent cells were transformed with plasmid and positive transformants were selected on LB agar supplemented with $30 \mu \mathrm{g} / \mathrm{mL}$ 
kanamycin. A single colony was transferred to LB (3 mL) supplemented with kanamycin $\left(30 \mu \mathrm{g} / \mathrm{mL}\right.$ ) and grown at $37^{\circ} \mathrm{C}$ and $250 \mathrm{rpm}$ overnight. The culture was used to inoculate LB media (1 L) supplemented with kanamycin $(30 \mu \mathrm{g} / \mathrm{mL})$. One liter culture was incubated at $37^{\circ} \mathrm{C}$ and $250 \mathrm{rpm}$ to an $\mathrm{OD}_{600}$ of 0.6 , at which time protein synthesis was induced by the addition of IPTG to a final concentration of $1 \mathrm{mM}$. After incubation at $18{ }^{\circ} \mathrm{C}$ and $200 \mathrm{rpm}$ for $18 \mathrm{~h}$, cells were collected by centrifugation at $5,000 \mathrm{~g}$ for $20 \mathrm{~min}$, and resuspended in $100 \mathrm{mM}$ Tris-HCl pH $8.0(20 \mathrm{~mL})$ containing $\mathrm{NaCl}(300 \mathrm{mM})$ and then lysed by sonication. Following centrifugation at $10,000 \mathrm{~g}$, the soluble extract was loaded onto a $1 \mathrm{~mL}$ HisTrap HP column (GE Healthcare, Piscataway, NJ) and purified by fast protein liquid chromatography using the following buffers: wash buffer $[20 \mathrm{mM}$ sodium phosphate $(\mathrm{pH}$ 7.4) containing $0.5 \mathrm{M} \mathrm{NaCl}$ and $20 \mathrm{mM}$ imidazole] and elution buffer [20 mM sodium phosphate ( $\mathrm{pH}$ 7.4) containing $0.5 \mathrm{M} \mathrm{NaCl}$ and $200 \mathrm{mM}$ imidazole]. The purified protein was concentrated using an Amicon Ultra $30 \mathrm{kDa}$ MWCO centrifugal filter (Millipore Corp., Billerica, MA) and stored as $10 \%$ glycerol stocks at $-80{ }^{\circ} \mathrm{C}$. Protein purity was verified by SDS-PAGE. Protein quantification was carried out using the Bradford Protein Assay Kit from Bio-Rad.

\section{Synthesis of Acyl-CoAs by MatB}

The MatB-catalyzed synthesis of extender units has been previously described. ${ }^{37,}, 38,44$ Briefly, reactions were performed in a $50 \mu \mathrm{L}$ reaction mixture containing $100 \mathrm{mM}$ sodium phosphate ( $\mathrm{pH} 7), \mathrm{MgCl}_{2}(2 \mathrm{mM})$, ATP $(12 \mathrm{mM})$, coenzyme A ( $\left.8 \mathrm{mM}\right)$, malonate or corresponding analogue $(16 \mathrm{mM})$ and wild-type or mutant MatB $(10 \mu \mathrm{g})$ at $25^{\circ} \mathrm{C}$. Aliquots were removed after $3 \mathrm{~h}$ incubation, and quenched with an equal volume of ice-cold methanol, centrifuged at 10,000 $\mathrm{g}$ for $10 \mathrm{~min}$, and cleared supernatants used for HPLC analysis on a Varian ProStar HPLC system. A series of linear gradients was developed from $0.1 \%$ TFA (A) in water to methanol (HPLC grade, B) using the following protocol: 0-32 $\min , 80 \% \mathrm{~B} ; 32-35 \mathrm{~min}, 100 \% \mathrm{~A}$. The flow rate was $1 \mathrm{~mL} / \mathrm{min}$, and the absorbance was monitored at $254 \mathrm{~nm}$ using Pursuit XRs C18 column $(250 \times 4.6 \mathrm{~mm}$, Varian Inc.). To ensure complete conversion, the malonate analog and the acyl-CoA product HPLC peak areas were integrated, and the conversion (\%) calculated as a percent of the total peak area. Product elution times and LC-MS data (data not shown) were in complete agreement with that previous described. ${ }^{37,44}$

\section{Synthesis of mmSNAC}

To access the previously reported mmSNAC, the a-carboxy group of the corresponding commercial methylmalonic acid was protected via esterification with ${ }^{\mathrm{t}} \mathrm{Bu}$, which was then thioesterified with HSNAC, and deprotected via hydrolysis to afford the acyl-SNAC. ${ }^{45-47}$ Full synthetic methods and product characterization can be found in the Supplemental Methods.

\section{Cell-Free Characterization of FapR Promiscuity}

A commercial kit for cell-free transcription-translation reactions was purchased from New England Biolabs (PURExpress In Vitro Protein Synthesis Kit). To a PCR tube on ice were added (in the order shown): $4 \mu \mathrm{L}$ Solution A, $3 \mu \mathrm{L}$ Solution B, $2.5 \mu \mathrm{M}$ FapR, $250 \mathrm{nM}$ T7fapO-sfGFP and $150 \mu \mathrm{M}$ of MatB-generated acyl-CoA or mmSNAC in a total volume of 10 
$\mu \mathrm{L}$. In parallel, control reactions in the absence of thioester were assembled by using boiled MatB. The reaction was incubated for $16 \mathrm{~h}$ at $37{ }^{\circ} \mathrm{C}$ and then diluted with PBS buffer to give a final total volume of $50 \mu \mathrm{L}$. Then, the diluted mixture was used for determination of the sfGFP fluorescence (ex $485 \mathrm{~nm} / \mathrm{em} 510 \mathrm{~nm}$ ) using a Tecan infinite F200 microplate spectrophotometer.

\section{FapR-Bioassay of Methylmalonyl-CoA Production in E. coli K207-3}

pSENSE2FF-2H8 was transformed into E. coli K207-3 and grown overnight in $1 \mathrm{~mL}$ volumes in a 96-deepwell microplate at $37{ }^{\circ} \mathrm{C}$ and $350 \mathrm{rpm}$. These cultures $(10 \mu \mathrm{L})$ were used to inoculate wells of a fresh 96-deepwell plate containing $440 \mu \mathrm{L} \mathrm{LB}$ and $100 \mu \mathrm{g} \mathrm{mL}^{-1}$ ampicillin which were then incubated at $37{ }^{\circ} \mathrm{C}$ and $350 \mathrm{rpm}$ for $2.5 \mathrm{~h}$. Various combinations of IPTG ( $1 \mathrm{mM}$ final concentration) and sodium propionate ( $1 \mathrm{mM}$ final concentration) were then added and the cultures incubated for $16 \mathrm{~h}$ at $37{ }^{\circ} \mathrm{C}$ and $350 \mathrm{rpm}$. The microplate was centrifuged at 3,500 rpm for $7 \mathrm{~min}$, and the supernatant was discarded. Cell pellets were resuspended in $1 \mathrm{~mL}$ PBS and $100 \mu \mathrm{L}$ of each cell suspension was transferred to flat-bottom 96-well plates and used for determining the optical density at $600 \mathrm{~nm}\left(\mathrm{OD}_{600}\right)$ and sfGFP fluorescence (ex $485 \mathrm{~nm} / \mathrm{em} 509 \mathrm{~nm}$ ). The fluorescence intensity was divided by the $\mathrm{OD}_{600}$ to yield a relative GFP fluorescence value.

\section{Purification of FapR}

E. coli BL21(DE3) competent cells were transformed with fapR_pET28a plasmid and positive transformants were selected on LB agar supplemented with $30 \mu \mathrm{g} / \mathrm{mL}$ kanamycin. A single colony was transferred to LB $(3 \mathrm{~mL})$ supplemented with kanamycin $(30 \mu \mathrm{g} / \mathrm{mL})$ and grown at $37^{\circ} \mathrm{C}$ and $250 \mathrm{rpm}$ overnight. The culture was used to inoculate LB media (300 $\mathrm{mL}$ ) supplemented with kanamycin $(30 \mu \mathrm{g} / \mathrm{mL})$. The culture was incubated at $37{ }^{\circ} \mathrm{C}$ and 250 rpm to an $\mathrm{OD}_{600}$ of 0.6 , at which time protein synthesis was induced by the addition of IPTG to a final concentration of $1 \mathrm{mM}$. After incubation at $22{ }^{\circ} \mathrm{C}$ and $250 \mathrm{rpm}$ for $20 \mathrm{~h}$, cells were collected by centrifugation at 5,000 $\mathrm{g}$ for $20 \mathrm{~min}$, and resuspended in $100 \mathrm{mM}$ Tris$\mathrm{HCl} \mathrm{pH} 8.0(8 \mathrm{~mL})$ containing $\mathrm{NaCl}(300 \mathrm{mM})$ and then lysed by sonication. Following centrifugation at $10,000 \mathrm{~g}$, the soluble extract was loaded onto a $1 \mathrm{~mL}$ HisTrap HP column (GE Healthcare, Piscataway, NJ) and purified by fast protein liquid chromatography using the following buffers: wash buffer [ $20 \mathrm{mM}$ sodium phosphate $(\mathrm{pH} 7.4)$ containing $0.5 \mathrm{M}$ $\mathrm{NaCl}$ and $20 \mathrm{mM}$ imidazole] and elution buffer [20 mM sodium phosphate ( $\mathrm{pH}$ 7.4) containing $0.5 \mathrm{M} \mathrm{NaCl}$ and $200 \mathrm{mM}$ imidazole]. The purified protein was concentrated using an Amicon Ultra $10 \mathrm{kDa}$ MWCO centrifugal filter (Millipore Corp., Billerica, MA) and stored in storage buffer (50 mM HEPES, pH 7.5, $100 \mathrm{mM} \mathrm{NaCl}$, and 10\% glycerol) at $-80{ }^{\circ} \mathrm{C}$. Protein purity was verified by SDS-PAGE. Protein quantification was carried out using the Bradford Protein Assay Kit from Bio-Rad.

\section{Supplementary Material}

Refer to Web version on PubMed Central for supplementary material.

\section{ACKNOWLEDGMENTS}

This study was supported in part by National Institutes of Health grants GM104258 and GM124112 (G.J.W.). 


\section{REFERENCES}

1. Kasey C, and Williams GJ (2018) Chapter 8: Customizing transcription-factor biosensors for modern biotechnology, In Modern Biocatalysis: Advances Towards Synthetic Biological Systems, pp 203-233, The Royal Society of Chemistry.

2. Carpenter AC, Paulsen IT, and Williams TC (2018) Blueprints for biosensors: design, limitations, and applications, Genes (Basel) 9.

3. Shi S, Ang EL, and Zhao H (2018) In vivo biosensors: mechanisms, development, and applications, J Ind Microbiol Biotechnol 45, 491-516. [PubMed: 29380152]

4. Kasey CM, Zerrad M, Li Y, Cropp TA, and Williams GJ (2018) Development of transcription factorbased designer macrolide biosensors for metabolic engineering and synthetic biology, ACS Synth. Biol 7, 227-239. [PubMed: 28950701]

5. Zhang F, Carothers JM, and Keasling JD (2012) Design of a dynamic sensor-regulator system for production of chemicals and fuels derived from fatty acids, Nat. Biotechnol 30, 354-359. [PubMed: 22446695]

6. Siedler S, Schendzielorz G, Binder S, Eggeling L, Bringer S, and Bott M (2014) SoxR as a singlecell biosensor for NADPH-consuming enzymes in Escherichia coli, ACS Synth. Biol 3, 41-47. [PubMed: 24283989]

7. Dahl RH, Zhang F, Alonso-Gutierrez J, Baidoo E, Batth TS, Redding-Johanson AM, Petzold CJ, Mukhopadhyay A, Lee TS, Adams PD, and Keasling JD (2013) Engineering dynamic pathway regulation using stress-response promoters, Nat. Biotechnol 31, 1039-1046. [PubMed: 24142050]

8. Johnson AO, Gonzalez-Villanueva M, Wong L, Steinbuchel A, Tee KL, Xu P, and Wong TS (2017) Design and application of genetically-encoded malonyl-CoA biosensors for metabolic engineering of microbial cell factories, Metab. Eng 44, 253-264. [PubMed: 29097310]

9. Fowler ZL, Gikandi WW, and Koffas MA (2009) Increased malonyl coenzyme A biosynthesis by tuning the Escherichia coli metabolic network and its application to flavanone production, Appl. Environ. Microbiol 75, 5831-5839. [PubMed: 19633125]

10. Leonard E, Yan Y, Fowler ZL, Li Z, Lim CG, Lim KH, and Koffas MA (2008) Strain improvement of recombinant Escherichia coli for efficient production of plant flavonoids, Mol Pharm 5, 257265. [PubMed: 18333619]

11. Walker MC, Thuronyi BW, Charkoudian LK, Lowry B, Khosla C, and Chang MC (2013) Expanding the fluorine chemistry of living systems using engineered polyketide synthase pathways, Science 341, 1089-1094. [PubMed: 24009388]

12. Dayem LC, Carney JR, Santi DV, Pfeifer BA, Khosla C, and Kealey JT (2002) Metabolic engineering of a methylmalonyl-CoA mutase-epimerase pathway for complex polyketide biosynthesis in Escherichia coli, Biochemistry 41, 5193-5201. [PubMed: 11955068]

13. Lombo F, Pfeifer B, Leaf T, Ou S, Kim YS, Cane DE, Licari P, and Khosla C (2001) Enhancing the atom economy of polyketide biosynthetic processes through metabolic engineering, Biotechnol. Prog 17, 612-617. [PubMed: 11485419]

14. Schujman GE, Paoletti L, Grossman AD, and de Mendoza D (2003) FapR, a bacterial transcription factor involved in global regulation of membrane lipid biosynthesis, Dev Cell 4, 663-672. [PubMed: 12737802]

15. Schujman GE, Guerin M, Buschiazzo A, Schaeffer F, Llarrull LI, Reh G, Vila AJ, Alzari PM, and de Mendoza D (2006) Structural basis of lipid biosynthesis regulation in Gram-positive bacteria, EMBO J. 25, 4074-4083. [PubMed: 16932747]

16. Albanesi D, Reh G, Guerin ME, Schaeffer F, Debarbouille M, Buschiazzo A, Schujman GE, de Mendoza D, and Alzari PM (2013) Structural basis for feed-forward transcriptional regulation of membrane lipid homeostasis in Staphylococcus aureus, PLoS Pathog 9, e1003108. [PubMed: 23300457]

17. Xu P, Li L, Zhang F, Stephanopoulos G, and Koffas M (2014) Improving fatty acids production by engineering dynamic pathway regulation and metabolic control, Proc. Natl. Acad. Sci. USA 111, 11299-11304. [PubMed: 25049420] 
18. Xu P, Wang W, Li L, Bhan N, Zhang F, and Koffas MA (2014) Design and kinetic analysis of a hybrid promoter-regulator system for malonyl-CoA sensing in Escherichia coli, ACS Chem. Biol 9, 451-458. [PubMed: 24191643]

19. Liu D, Xiao Y, Evans BS, and Zhang F (2015) Negative feedback regulation of fatty acid production based on a malonyl-CoA sensor-actuator, ACS Synth. Biol 4, 132-140. [PubMed: 24377365]

20. David F, Nielsen J, and Siewers V (2016) Flux control at the malonyl-CoA node through hierarchical dynamic pathway regulation in Saccharomyces cerevisiae, ACS Synth. Biol 5, 224 233. [PubMed: 26750662]

21. Li S, Si T, Wang M, and Zhao H (2015) Development of a synthetic malonyl-CoA sensor in Saccharomyces cerevisiae for intracellular metabolite monitoring and genetic screening, ACS Synth. Biol 4, 1308-1315. [PubMed: 26149896]

22. Ellis JM, and Wolfgang MJ (2012) A genetically encoded metabolite sensor for malonyl-CoA, Chem. Biol 19, 1333-1339. [PubMed: 23102226]

23. Murli S, Kennedy J, Dayem LC, Carney JR, and Kealey JT (2003) Metabolic engineering of Escherichia coli for improved 6-deoxyerythronolide B production, J Ind Microbiol Biotechnol 30, 500-509. [PubMed: 12898389]

24. Zhang H, Boghigian BA, and Pfeifer BA (2010) Investigating the role of native propionyl-CoA and methylmalonyl-CoA metabolism on heterologous polyketide production in Escherichia coli, Biotechnol. Bioeng 105, 567-573. [PubMed: 19806677]

25. Cai W, and Zhang W (2018) Engineering modular polyketide synthases for production of biofuels and industrial chemicals, Curr. Opin. Biotechnol 50, 32-38. [PubMed: 28946011]

26. Chan YA, Podevels AM, Kevany BM, and Thomas MG (2009) Biosynthesis of polyketide synthase extender units, Nat. Prod. Rep 26, 90. [PubMed: 19374124]

27. Penumetcha P, Lau K, Zhu X, Davis K, Eckdahl TT, and Campbell AM (2010) Improving the Lac system for synthetic biology, BIOS 81, 7-15.

28. Shaner NC, Lambert GG, Chammas A, Ni Y, Cranfill PJ, Baird MA, Sell BR, Allen JR, Day RN, Israelsson M, Davidson MW, and Wang J (2013) A bright monomeric green fluorescent protein derived from Branchiostoma lanceolatum, Nat. Methods 10, 407-409. [PubMed: 23524392]

29. Price AC, Choi KH, Heath RJ, Li Z, White SW, and Rock CO (2001) Inhibition of beta-ketoacylacyl carrier protein synthases by thiolactomycin and cerulenin. Structure and mechanism, J. Biol. Chem 276, 6551-6559. [PubMed: 11050088]

30. Espah Borujeni A, Channarasappa AS, and Salis HM (2014) Translation rate is controlled by coupled trade-offs between site accessibility, selective RNA unfolding and sliding at upstream standby sites, Nucleic Acids Res. 42, 2646-2659. [PubMed: 24234441]

31. Salis HM, Mirsky EA, and Voigt CA (2009) Automated design of synthetic ribosome binding sites to control protein expression, Nat. Biotechnol 27, 946-950. [PubMed: 19801975]

32. Farasat I, Kushwaha M, Collens J, Easterbrook M, Guido M, and Salis HM (2014) Efficient search, mapping, and optimization of multi-protein genetic systems in diverse bacteria, Mol. Syst. Biol 10, 731. [PubMed: 24952589]

33. Pizer ES, Thupari J, Han WF, Pinn ML, Chrest FJ, Frehywot GL, Townsend CA, and Kuhajda FP (2000) Malonyl-coenzyme-A is a potential mediator of cytotoxicity induced by fatty-acid synthase inhibition in human breast cancer cells and xenografts, Cancer Res. 60, 213-218. [PubMed: 10667561]

34. Thupari JN, Pinn ML, and Kuhajda FP (2001) Fatty acid synthase inhibition in human breast cancer cells leads to malonyl-CoA-induced inhibition of fatty acid oxidation and cytotoxicity, Biochem. Biophys. Res. Commun 285, 217-223. [PubMed: 11444828]

35. Nagaraj VH, Greene JM, Sengupta AM, and Sontag ED (2017) Translation inhibition and resource balance in the TX-TL cell-free gene expression system, Synthetic Biology 2.

36. Wang H, Jewett MC, and Li J (2018) Development of a Pseudomonas putida cell-free protein synthesis platform for rapid screening of gene regulatory elements, Synthetic Biology 3.

37. Koryakina I, McArthur J, Randall S, Draelos MM, Musiol EM, Muddiman DC, Weber T, and Williams GJ (2013) Poly specific trans-acyltransferase machinery revealed via engineered acylCoA synthetases, ACS Chem. Biol 8, 200-208. [PubMed: 23083014] 
38. Koryakina I, and Williams GJ (2011) Mutant malonyl-CoA synthetases with altered specificity for polyketide synthase extender unit generation, ChemBioChem 12, 2289-2293. [PubMed: 23106079]

39. Martinez MA, Zaballa ME, Schaeffer F, Bellinzoni M, Albanesi D, Schujman GE, Vila AJ, Alzari PM, and de Mendoza D (2010) A novel role of malonyl-ACP in lipid homeostasis, Biochemistry 49, 3161-3167. [PubMed: 20201588]

40. Rodriguez E, and Gramajo H (1999) Genetic and biochemical characterization of the alpha and beta components of a propionyl-CoA carboxylase complex of Streptomyces coelicolor A3(2), Microbiology 145 (Pt 11), 3109-3119. [PubMed: 10589718]

41. Taylor ND, Garruss AS, Moretti R, Chan S, Arbing MA, Cascio D, Rogers JK, Isaacs FJ, Kosuri S, Baker D, Fields S, Church GM, and Raman S (2016) Engineering an allosteric transcription factor to respond to new ligands, Nat. Methods 13, 177-183. [PubMed: 26689263]

42. Vogeli B, Geyer K, Gerlinger PD, Benkstein S, Cortina NS, and Erb TJ (2018) Combining promiscuous acyl-CoA oxidase and enoyl-CoA carboxylase/reductases for atypical polyketide extender unit biosynthesis, Cell Chem Biol 25, 833-839 e834. [PubMed: 29731424]

43. Peter DM, Vogeli B, Cortina NS, and Erb TJ (2016) A Chemo-Enzymatic Road Map to the Synthesis of CoA Esters, Molecules 21.

44. Koryakina I, McArthur JB, Draelos MM, and Williams GJ (2013) Promiscuity of a modular polyketide synthase towards natural and non-natural extender units, Org. Biomol. Chem 11, 44494458. [PubMed: 23681002]

45. Hansen DA, Rath CM, Eisman EB, Narayan AR, Kittendorf JD, Mortison JD, Yoon YJ, and Sherman DH (2013) Biocatalytic synthesis of pikromycin, methymycin, neomethymycin, novamethymycin, and ketomethymycin, J. Am. Chem. Soc 135, 11232-11238. [PubMed: 23866020]

46. Li Y, Zhang W, Zhang H, Tian W, Wu L, Wang S, Zheng M, Zhang J, Sun C, Deng Z, Sun Y, Qu $\mathrm{X}$, and Zhou J (2018) Structural basis of a broadly selective acyltransferase from the polyketide synthase of splenocin, Angew. Chem. Int. Ed. Engl 57, 5823-5827. [PubMed: 29536601]

47. Mo S, Kim DH, Lee JH, Park JW, Basnet DB, Ban YH, Yoo YJ, Chen SW, Park SR, Choi EA, Kim E, Jin YY, Lee SK, Park JY, Liu Y, Lee MO, Lee KS, Kim SJ, Kim D, Park BC, Lee SG, Kwon HJ, Suh JW, Moore BS, Lim SK, and Yoon YJ (2011) Biosynthesis of the allylmalonylCoA extender unit for the FK506 polyketide synthase proceeds through a dedicated polyketide synthase and facilitates the mutasynthesis of analogues, J. Am. Chem. Soc 133, 976-985.

[PubMed: 21175203] 


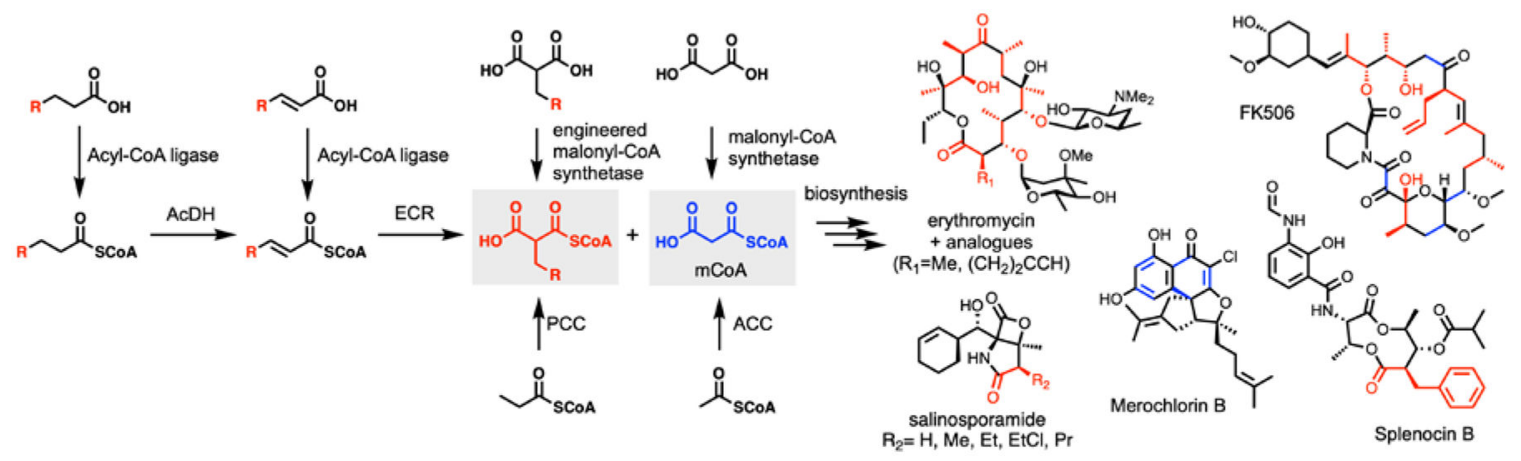

Figure 1.

Biosynthesis and uses of malonyl-CoA analogues. Natural and engineered biosynthetic pathways for mCoA (1) and derivatives involve acyl-CoA ligases, acetyl-CoA dehydrogenases (AcDH), enoyl-CoA-reductases (ECR), malonyl-CoA synthetases, and various acyl-CoA carboxylases (propionyl-CoA carboxylase, PCC; acetyl-CoA carboxylase, ACC). Co-substrates and cofactors are omitted for clarity. Examples of clinically-relevant compounds that utilize malonyl-CoA and its derivatives are shown. 


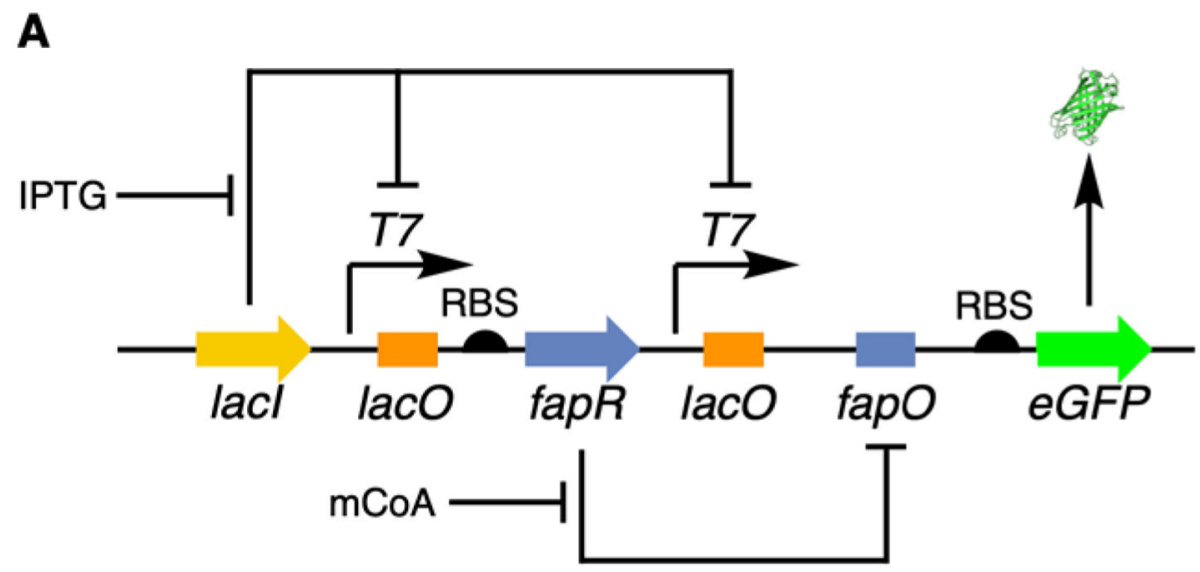

B

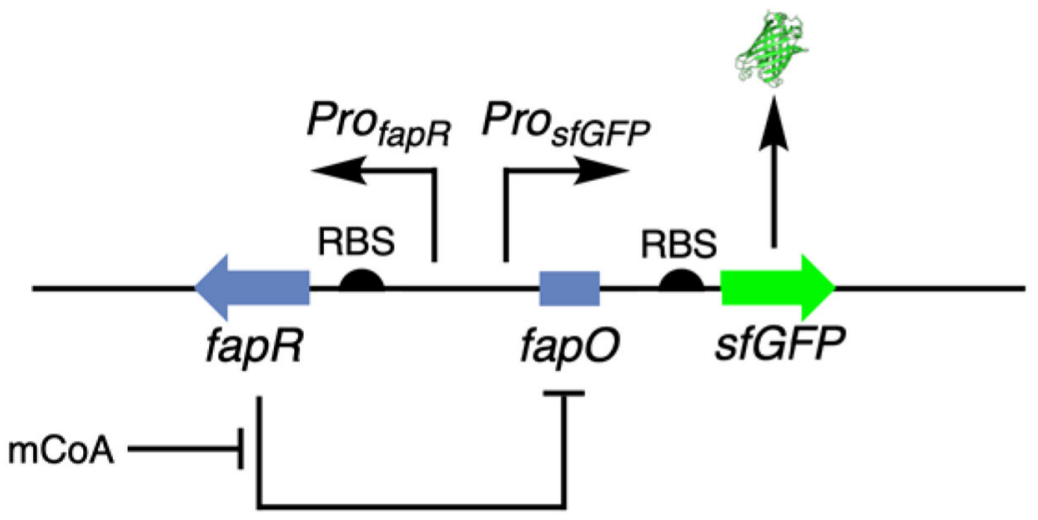

Figure 2.

Redesigned malonyl-CoA biosensor. (A) Scheme showing a previous synthetic gene circuit regulated by IPTG and mCoA. (B) Scheme showing a redesigned synthetic gene circuit regulated only by $\mathrm{mCoA}$. At low levels of $\mathrm{mCoA}$, FapR binds to its cognate operator and represses transcription. At increased levels, mCoA binds to FapR and causes a conformational change, allowing transcription of a fluorescent reporter gene. IPTG, isopropyl $\beta$-D-1-thiogalactopyranoside; lacI, E. coli lactose repressor; T7, bacteriophage T7 promoter; lacO, lacI repressor binding site; RBS, ribosome binding site; fapR, B. subtilis fatty acid biosynthetic pathway repressor; fapO, FapR repressor binding site; eGFP, enhanced GFP; mCoA, malonyl-CoA; Pro fapR/sfGFP, constituitive lac promoters; $s f G F$, superfolder GFP. 


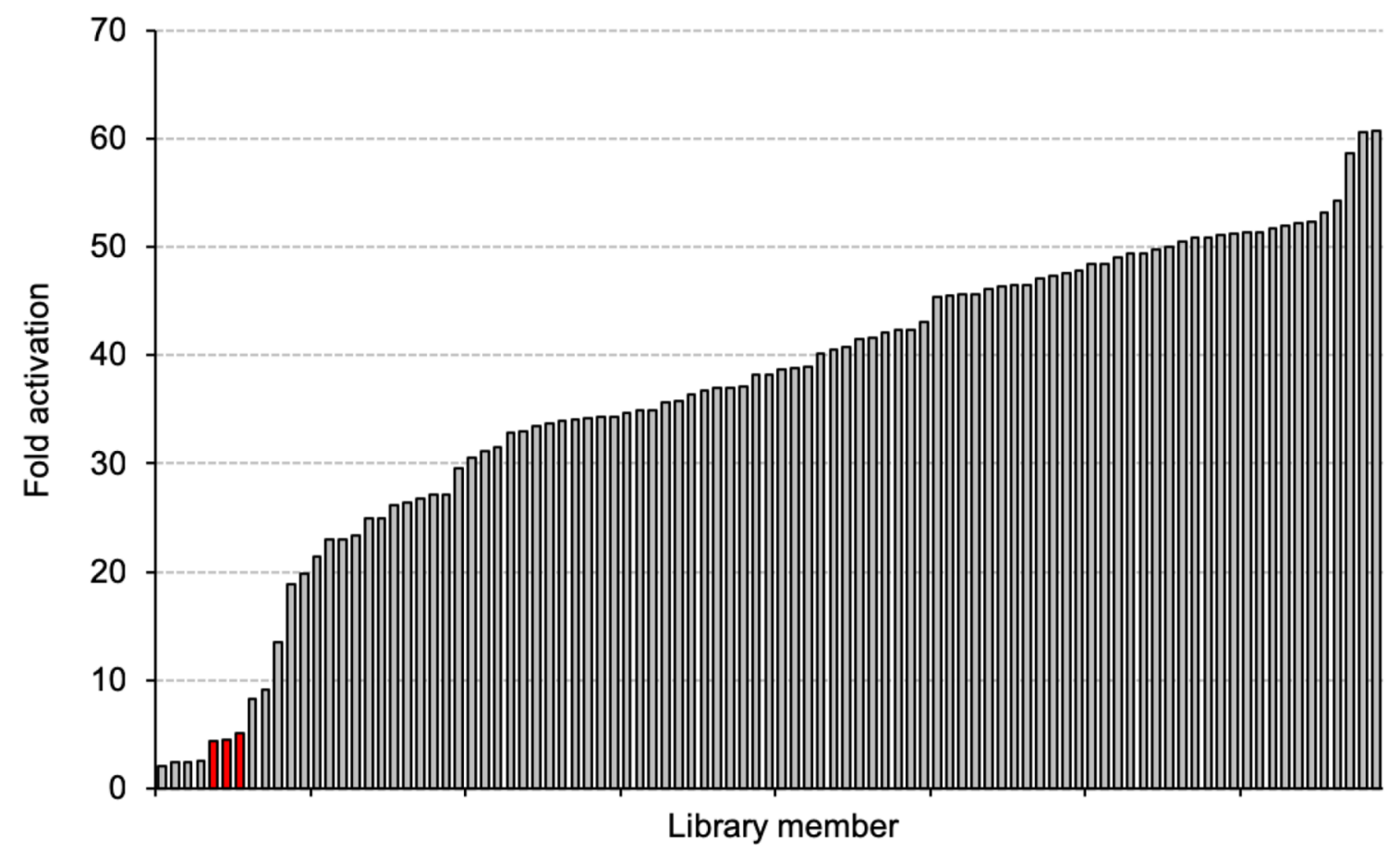

Figure 3.

Activation ratios of 93 variants from the FapR RBS library in E. coli 10G. The relative fluorescence (normalized to cell density) of each variant was determined at $0 \mu \mathrm{M}$ and $25 \mu \mathrm{M}$ cerulenin and divided to determine the fold activation. These values were compared with replicates $(n=3)$ of the prototype biosensor RBS (1A1, red). 


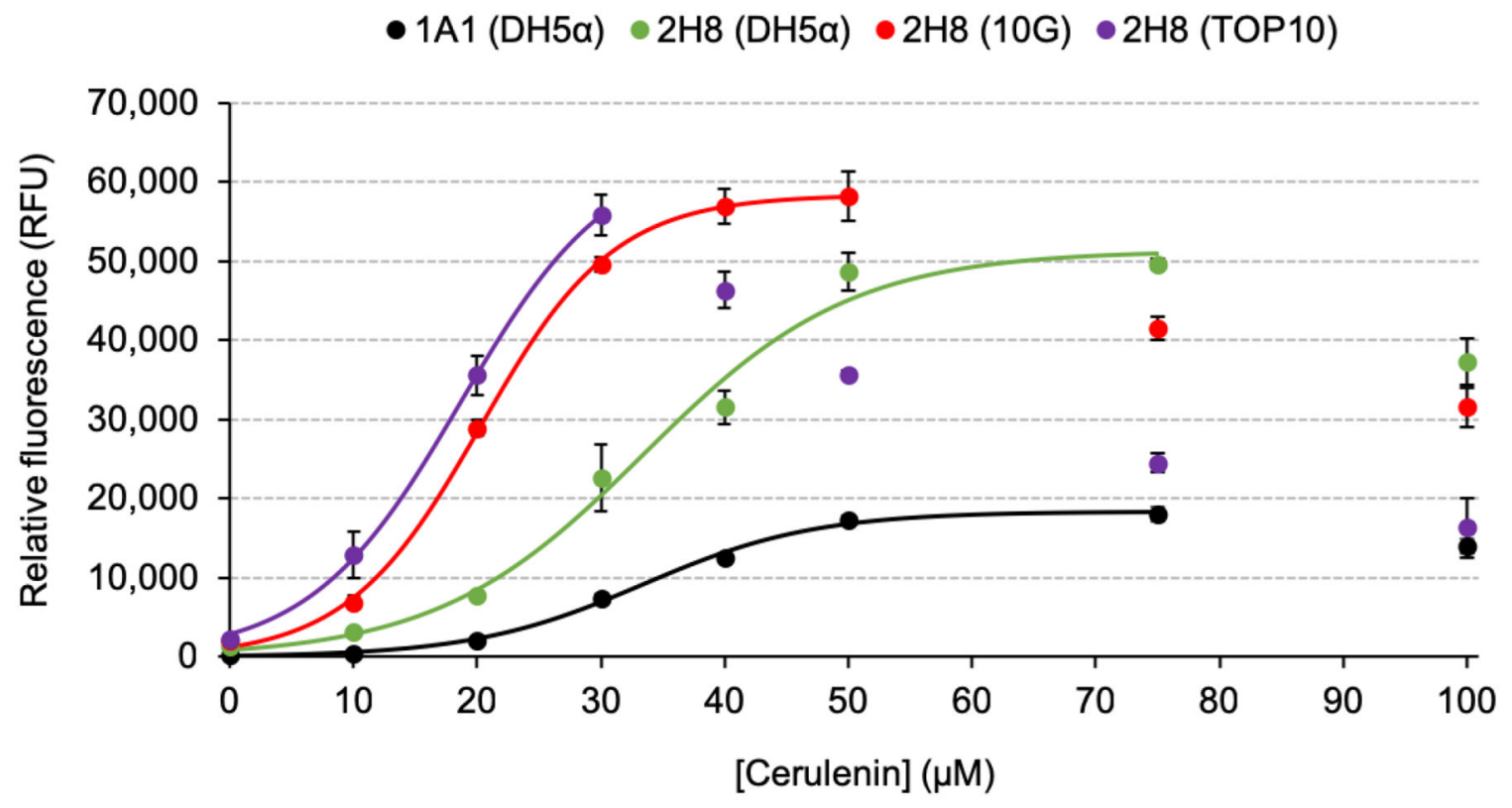

Figure 4.

Cerulenin dose-response curves of the FapR biosensor in various E. coli strains. The relative fluorescence (normalized to cell density) was determined at each indicated cerulenin concentration and the curves were fit to the Hill equation. Error bars (where visible) are the standard deviation of the mean (3 biological replicates). 
A
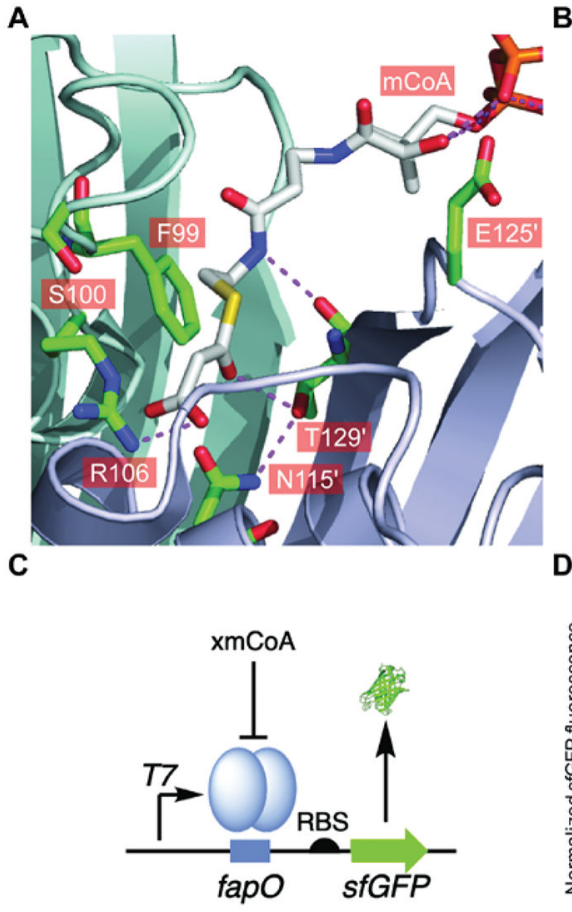

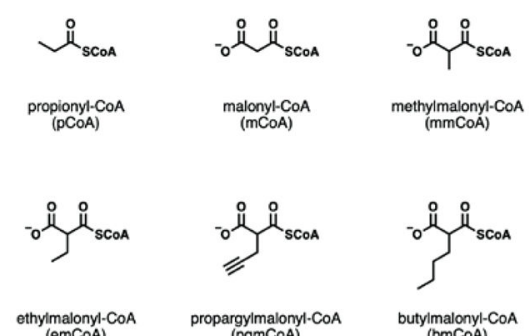

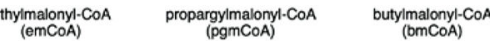

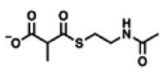

methylmalonyl-SNAC
(mmSNAC)

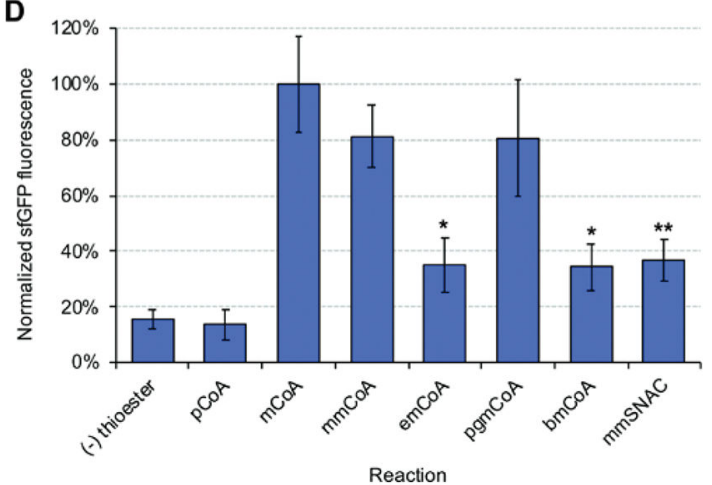

Figure 5.

Probing the effector promiscuity of FapR with malonyl-CoA derivatives by cell-free transcription-translation. (A) The mCoA-binding pocket of FapR (PDB: 2F3X) with key residues highlighted (green sticks). Dashed lines are hydrogen bonds (purple). The bound $\mathrm{mCoA}$ is shown (white sticks). The ribbon structure of each subunit of the homodimer is shown in light green and light cyan. (B) Structures of each analogue tested with FapR. (C) Scheme showing the layout of the cell-free biosensor, pET28a-T7-fapO-sfGFP. (D) Fluorescence output of the cell-free biosensor pET28a-FapR/T7-fapO-sfGFP in the presence of each thioester at $200 \mu \mathrm{M}$. The output in the presence of the native effector mCoA is set to $100 \%$. The (-) thioester control is boiled MatB. Error bars are the standard deviation of the mean ( 3 biological replicates). ${ }^{*} p<0.05$ by Student's unpaired two-tailed t-test vs. ( - ) thioester control. ${ }^{* *} p<0.01$ by Student's unpaired two-tailed t-test vs. (-) thioester control. 


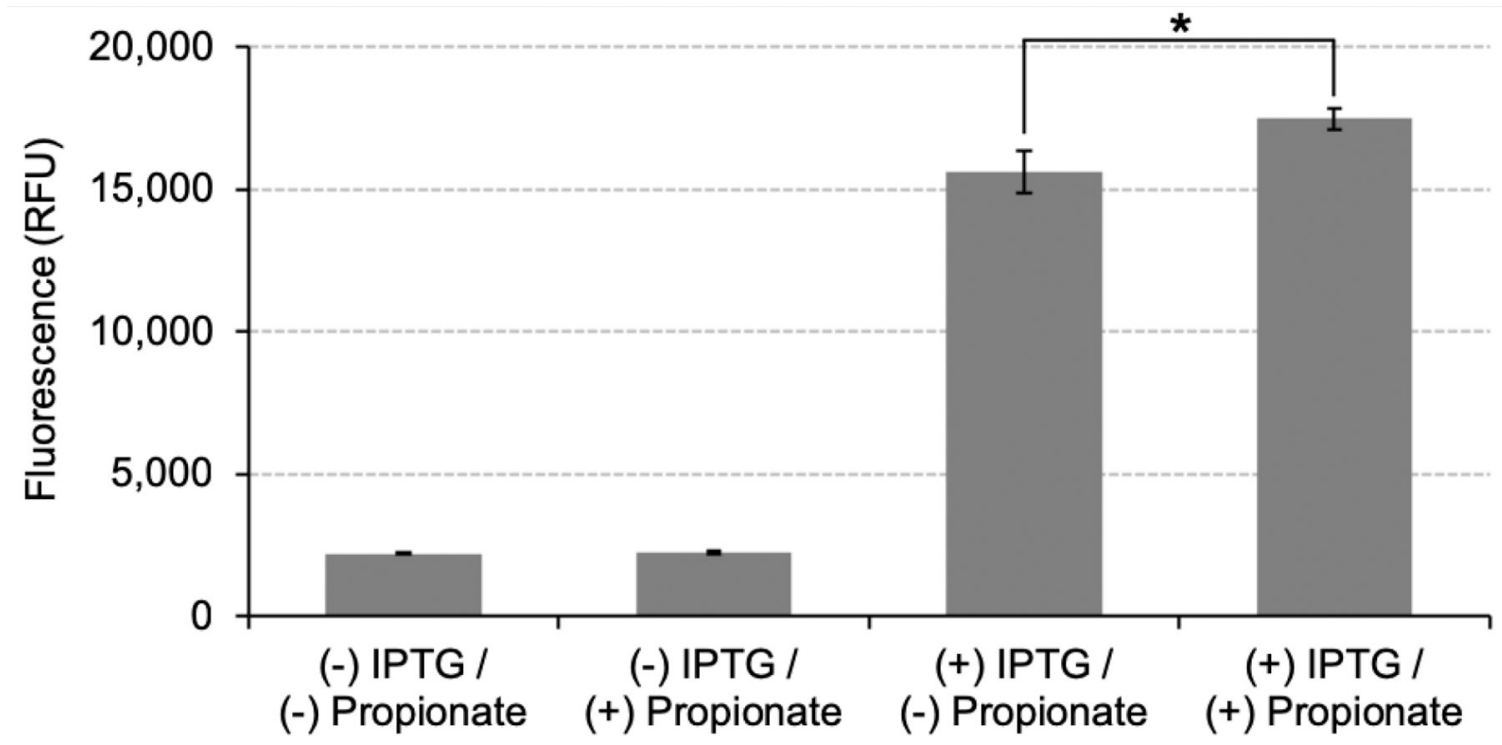

Figure 6.

Detection of mmCoA in E. coli K207-3 by FapR 2H8. Fluorescence output of the 2H8 biosensor was determined in the absence/presence of $1 \mathrm{mM}$ IPTG / $1 \mathrm{mM}$ propionate supplemented to the growth media. Error bars represent the standard deviation of three independent biological replicates. * $p<0.05$ by Student's unpaired two-tailed t-test. 
Table 1.

Biosensor Parameters in Various E. coli Strains.

\begin{tabular}{|c|c|c|c|c|c|c|c|c|}
\hline biosensor & RBS sequence ${ }^{a}$ & $\begin{array}{l}\text { TIR } \\
\text { (au) }\end{array}$ & $\begin{array}{l}\text { E. coli } \\
\text { strain }\end{array}$ & $\mathrm{GFP}_{\min }{ }^{c}$ & GFP $_{\max }{ }^{d}$ & $\begin{array}{c}\text { [Cerulenin] } \\
\quad(\mu \mathrm{M})^{e}\end{array}$ & $K_{1 / 2}(\mu \mathrm{M})^{f}$ & activation ratio ${ }^{g}$ \\
\hline $1 \mathrm{~A} 1$ & CAAGGAGGT & 7,594 & DH5a & $236 \pm 2$ & $18,000 \pm 900$ & 75 & $33.4 \pm 0.5$ & $77 \pm 4$ \\
\hline $2 \mathrm{H} 8$ & $\underline{T A C A C A G G \underline{C}}$ & 171 & DH5a & $1,442 \pm 44$ & $50,000 \pm 700$ & 75 & $33.5 \pm 1.1$ & $34 \pm 1$ \\
\hline $2 \mathrm{H} 8$ & $\underline{T A C A C A G G \underline{C}}$ & 171 & $10 \mathrm{G}$ & $2,031 \pm 127$ & $58,000 \pm 3,000$ & 50 & $20.3 \pm 0.4$ & $29 \pm 2$ \\
\hline $2 \mathrm{H} 8$ & $\underline{T A C A C A G G \underline{C}}$ & 171 & TOP10 & $2,203 \pm 72$ & $56,000 \pm 2,500$ & 30 & $18.6 \pm 1.0$ & $25 \pm 1$ \\
\hline
\end{tabular}

${ }^{a}$ Mutated nucleotides are underlined.

$b_{\text {Transcription initiation rate (arbituary units). }}$

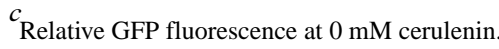

$d_{\text {Highest measured relative GFP fluorescence. }}$

${ }^{e}$ Concentration of cerulenin that produced the highest measured relative GFP fluorescence.

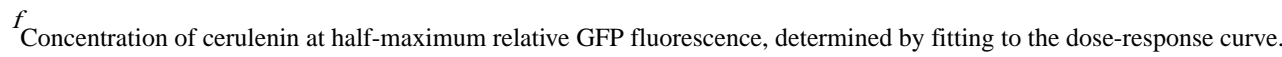

$g_{\mathrm{GFP}_{\max } / \mathrm{GFP}_{\min }}$ 